\title{
Exercise and insulin resistance in PCOS: muscle insulin signalling and fibrosis
}

\author{
N K Stepto 1,2,3,4,*, D Hiam 1,*, M Gibson-Helm², S Cassar ${ }^{1}$, C L Harrison², S K Hutchison ${ }^{2}$, A E Joham² , B J Canny ${ }^{5}$, \\ A Moreno-Asso ${ }^{1,3}$, B J Strauss ${ }^{6,7}$, N Hatzirodos ${ }^{8}$, R J Rodgers ${ }^{8}$ and H J Teede $^{2,9}$ \\ 'Institute for Health and Sport, Victoria University, Melbourne, Victoria, Australia \\ ${ }^{2}$ Monash Centre for Health Research and Implementation, Monash University, Clayton, Victoria, Australia \\ ${ }^{3}$ Australian Institute for Musculoskeletal Science, Victoria University, Melbourne, Victoria, Australia \\ ${ }^{4}$ Medicine-Western Health, Faculty of Medicine, Dentistry and Health Science, Melbourne University, Melbourne, Victoria, Australia \\ ${ }_{5}^{5}$ School of Medicine, University of Tasmania, Hobart, Tasmania, Australia \\ ${ }^{6}$ Department of Medicine, School of Clinical Sciences, Monash University, Clayton, Victoria, Australia \\ ${ }^{7}$ Division of Diabetes, Endocrinology \& Gastroenterology, School of Medical Sciences, Faculty of Biology, Medicine and Health, The University of \\ Manchester, Manchester, UK \\ ${ }^{8}$ The Robinson Research Institute, School of Medicine, The University of Adelaide, Adelaide, Australia \\ ${ }^{9}$ Diabetes and Endocrine Units, Monash Health, Clayton, Victoria, Australia
}

Correspondence should be addressed to D Hiam: Danielle.hiam@vu.edu.au

*(N K Stepto and D Hiam contributed equally to this work)

\begin{abstract}
Objective: Mechanisms of insulin resistance in polycystic ovary syndrome (PCOS) remain ill defined, contributing to sub-optimal therapies. Recognising skeletal muscle plays a key role in glucose homeostasis we investigated early insulin signalling, its association with aberrant transforming growth factor $\beta$ (TGF $\beta$ )-regulated tissue fibrosis. We also explored the impact of aerobic exercise on these molecular pathways.

Methods: A secondary analysis from a cross-sectional study was undertaken in women with $(n=30)$ or without $(n=29)$ PCOS across lean and overweight BMls. A subset of participants with $(n=8)$ or without $(n=8)$ PCOS who were overweight completed 12 weeks of aerobic exercise training. Muscle was sampled before and 30 min into a euglycaemic-hyperinsulinaemic clamp pre and post training.

Results: We found reduced signalling in PCOS of mechanistic target of rapamycin (mTOR). Exercise training augmented but did not completely rescue this signalling defect in women with PCOS. Genes in the TGF $\beta$ signalling network were upregulated in skeletal muscle in the overweight women with PCOS but were unresponsive to exercise training except for genes encoding LOX, collagen 1 and 3.

Conclusions: We provide new insights into defects in early insulin signalling, tissue fibrosis, and hyperandrogenism in PCOS-specific insulin resistance in lean and overweight women. PCOS-specific insulin signalling defects were isolated to mTOR, while gene expression implicated TGF $\beta$ ligand regulating a fibrosis in the PCOS-obesity synergy in insulin resistance and altered responses to exercise. Interestingly, there was little evidence for hyperandrogenism as a mechanism for insulin resistance.
\end{abstract}

\section{Key Words}

- mechanistic target of rapamysin (mTOR)

- typical and atypical protein kinase $\mathrm{C}$

- transforming growth factor $\beta$ receptor 2 (TGFBRII)

- collagen

treadmill exercise training

- high intensity interval training

- hyperandrogenism https://ec.bioscientifica.com

https://doi.org/10.1530/EC-19-0551 (c) 2020 The authors Published by Bioscientifica Ltd

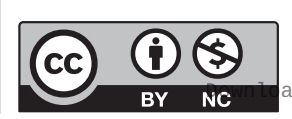

This work is licensed under a Creative Commons Attribution-NonCommercial 4.0 International License. ded from Bioscientifica.com at 04/26/2023 09:24:23AM
Endocrine Connections (2020) 9, 346-359 


\section{Introduction}

Polycystic ovary syndrome (PCOS) affects $8-13 \%$ of women of reproductive age (1) has major metabolic (increased type 2 diabetes mellitus (T2D) and cardiovascular risk factors) $(2,3,4)$, reproductive (leading cause of anovulatory infertility) $(5,6)$ and psychological (anxiety and depression) (7) impacts, representing a substantial health burden. Despite its high prevalence, the aetiology and ideal therapies for PCOS remain unclear (8). Insulin resistance is a central characteristic $(9,10)$, driving both hyperandrogenism and clinical features. The risk of T2D in PCOS is increased 4.4-fold independent of BMI $(3,4,11)$ accounting for $23 \%$ of T2D in young women (12); yet, the underlying mechanisms of insulin resistance in PCOS remain ill defined (8, 13). Therapeutic strategies in PCOS include medical therapy (metformin) and weight management via diet and exercise $(6,14,15)$, which reduce but not reverse insulin resistance and fail to optimally treat PCOS. In this context, greater insight into aetiology of insulin resistance in PCOS is needed.

Based on euglycaemic-hyperinsulinaemic clamp data, prevalence of insulin resistance has been reported in up to $95 \%$ of women with PCOS as diagnosed by Rotterdam criteria (9). PCOS has a unique PCOSrelated insulin resistance (intrinsic insulin resistance) as $75 \%$ of lean PCOS are insulin resistant, compared to lean women without PCOS. This insulin resistance is exacerbated by obesity (extrinsic insulin resistance (9, $10,13)$ ). Intrinsic insulin resistance in PCOS is likely due to a dysfunctional response to insulin in metabolically active peripheral tissues including adipose tissue and skeletal muscle $(8,13)$. As skeletal muscle accounts for $70-80 \%$ of insulin-stimulated glucose uptake (16) defects may have profound effects on whole body insulin sensitivity. Reduced insulin sensitivity in skeletal muscle has well-established mechanisms including defective insulin signalling $(17,18)$, with reduced activation of key signalling proteins such as insulin receptor substrate (IRS) $1 / 2$, protein kinase B (PKB)/Akt and its downstream substrate Akt substrate 160KDa (AS160) $(17,18,19)$. While similar defects in insulin stimulated signalling have been found in women with PCOS $(13,20)$, these signalling defects are not consistent (21) and unable to explain the PCOS-specific IR.

Raja-Khan et al. (22) has proposed an alternative hypothesis that dysfunctional transforming growth factor $\beta$ (TGF $\beta$ ) signalling regulated by fibrillins and latent TGF $\beta$-binding proteins may lead to increased organ stroma or fibrosis. This may predispose women with PCOS to morbidities like insulin resistance, as TGF $\beta$ can directly impact glucose uptake and insulin signalling $(23,24,25)$ and/or create a physical barrier to glucose uptake into muscle (26). The role of aberrant extracellular matrix (ECM) remodelling or tissue fibrosis and TGF $\beta$ in the aetiology of PCOS-related insulin resistance has not been investigated.

We therefore hypothesised that the women with PCOS compared to BMI-matched controls would be associated with unique defects in insulin signal transduction and altered ECM and TGF $\beta$ signalling network gene expression. We aimed to examine the activation/phosphorylation of proteins in both the proximal and distal parts of the insulin signalling cascade before and $30 \mathrm{~min}$ into a euglycaemic-hyperinsulinaemic insulin clamp and gene expression of the ECM and TGF $\beta$ ligand signalling network in women with or without PCOS (spanning lean and obese BMIs). Our secondary aim was to investigate the impact of exercise training on the aberrant skeletal muscle insulin signalling and gene expression of the ECM and TGF $\beta$ ligand signalling network.

\section{Materials and methods}

\section{Participants}

The participants that are included in this secondary analysis are a subset of women who participated in our previously published studies $(9,27,28,29)$ and consented to muscle biopsies. Specifically, we included fifty-nine (Fig. 1 and Table 1) of the original cohort of premenopausal women with or without PCOS. The women were categorised according to PCOS status and matched (group means) for BMI generating four groups: (i) lean with PCOS (LP), (ii) lean without (control; LC), (iii) overweight to obese with PCOS (OWP) and (iv) overweight to obese without PCOS (control; OWC). Confirmation of PCOS diagnosis was undertaken by expert endocrinologists (SKH, AEJ and HJT) based on Rotterdam criteria. The Southern Health Research Advisory and Ethics Committee approved the study and participants gave written informed consent. The clinical trial registration number is ISRCTN84763265.

\section{Study design}

For this ancillary mechanistic observational study and interventional sub-study (Fig. 1) data were collected

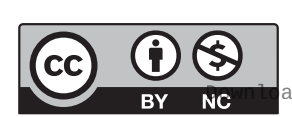

This work is licensed under a Creative Commons Attribution-NonCommercial 4.0 International License. ded from Bioscientifica.com at 04/26/2023 09:24:23AM 


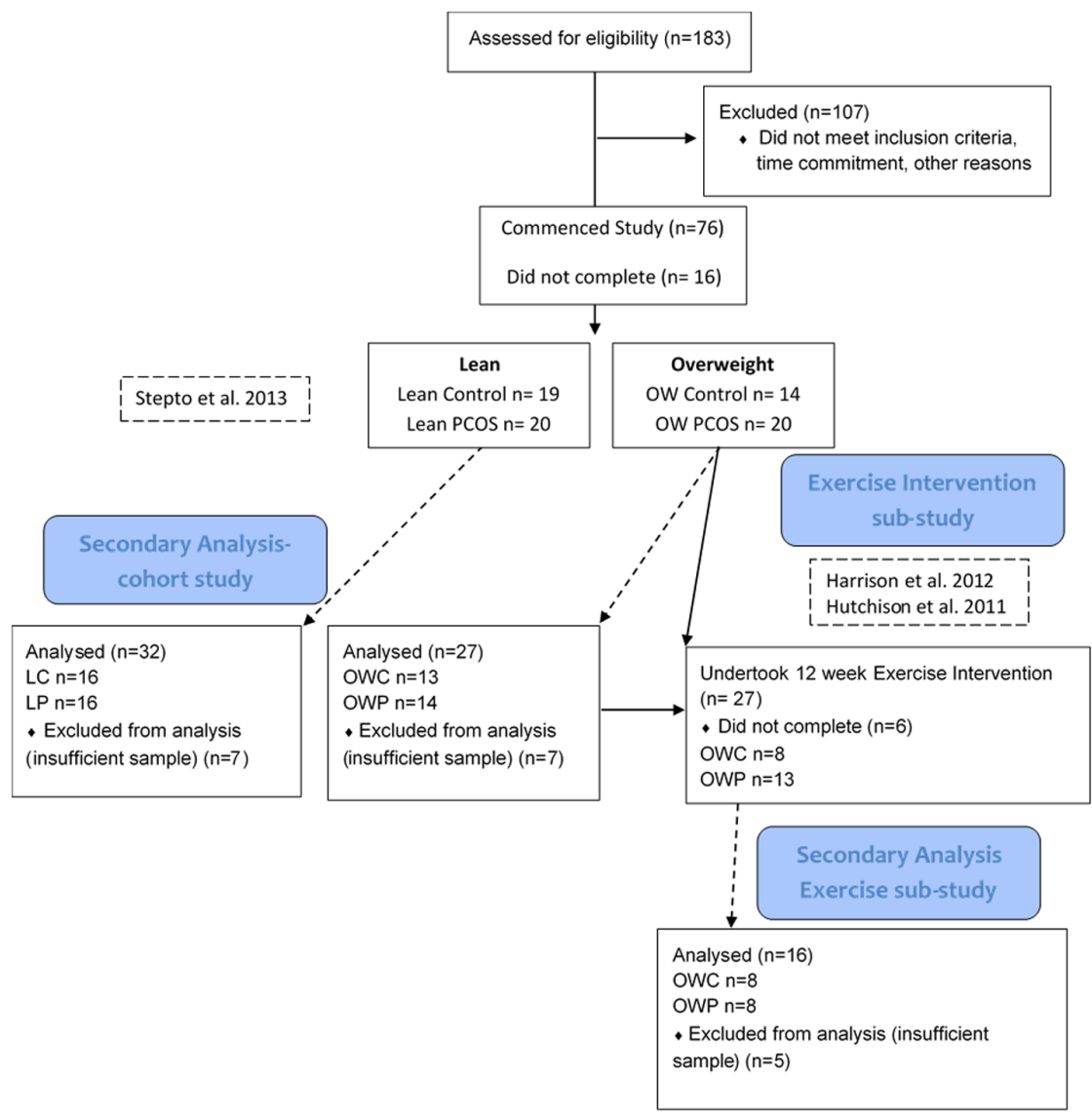

\section{Figure 1}

Consort flow diagram detailing the sample size and prior research studies for the secondary analysis reported in the current study. at baseline in all women (after three-month washout of relevant medications) and following 12 weeks of exercise training (subgroup of women with overweight/ obesity $n=8$ per group). Data were collected in the follicular phase of the menstrual cycle in control women and wherever feasible in the women with PCOS. Endpoint analyses were done by staff blinded to group and intervention stage.

\section{Exercise intervention}

The subgroup of overweight to obese participants consisting of women with PCOS $(n=8)$ and without PCOS (controls; $n=8$ ) undertook 12 weeks of supervised, personalised progressive, aerobic exercise training on a motorised treadmill as described previously. Briefly, participants attended three $1 \mathrm{~h}$ sessions each week, which sequentially alternated between moderate-intensity (walking or jogging at $70 \%$ of $\mathrm{VO}_{2}$ peak or $75-85 \% \mathrm{HRmax}$ ) and high-intensity interval training (six 5-min intervals with 2-min recovery period at approximately $95-100 \%$ of $\mathrm{VO}_{2}$ peak or approximately $95-100 \%$ HRmax). The intensity and/or duration of each participant's exercise session were individually progressed and increased over the duration of the intervention $(28,29,30)$.

\section{Clinical and biochemical measurements}

Participants were assessed for anthropometric measures including body weight, height, body composition, abdominal visceral fat and subcutaneous fat and, waist, and hip circumference as Table 1 . Insulin sensitivity was determined using the euglycaemic-hyperinsulinaemic clamp technique ( $40 \mathrm{mU} / \mathrm{m}^{2} / \mathrm{min}$ ) as previously reported (9). Blood samples were batch analysed for fasting glucose, total cholesterol, high-density lipoprotein cholesterol, low-density lipoprotein cholesterol, triglycerides, insulin, testosterone and HbA1c. Lowdensity lipoprotein and the homeostatic model insulin resistance assessment (HOMA) were calculated (31).

Thigh muscle (vastus lateralis) samples were obtained by percutaneous biopsy under local anaesthesia (29) immediately prior to and 30 min into the insulin clamp. Muscle biopsies were immediately frozen in liquid nitrogen and then stored at $-80^{\circ} \mathrm{C}$ for subsequent analysis.
This work is licensed under a Creative Commons Attribution-NonCommercial 4.0 International License. ded from Bioscientifica.com at 04/26/2023 09:24:23AM via free access 
$\stackrel{+1}{m}$

年宇

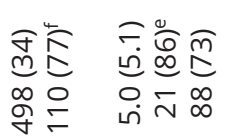

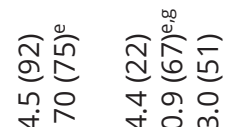

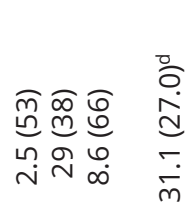

|

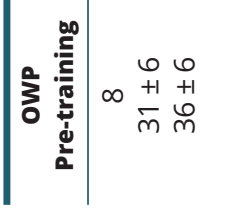

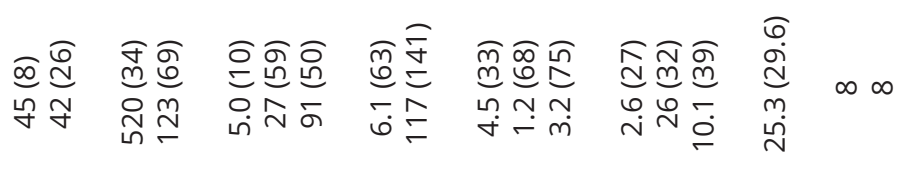

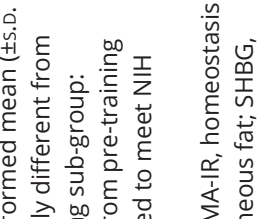

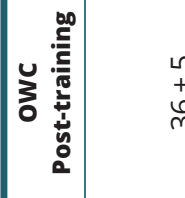

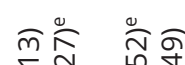

ชำ

$\sigma \frac{0}{0}$

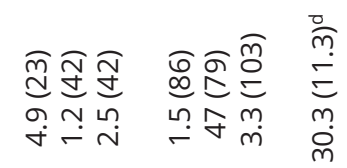

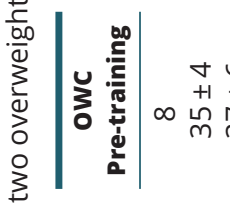

市

กํํำ

$\stackrel{\infty}{+\infty}$

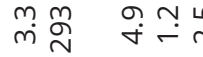

ิำ คิ

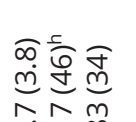

选售点

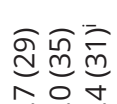

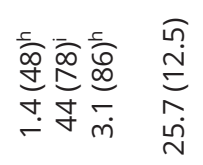

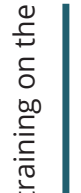

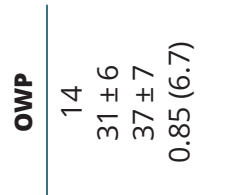

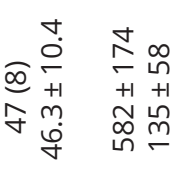

$\leftrightarrow \stackrel{\infty}{\sim}+$

m $\underset{\sim}{\sim} \stackrel{\sim}{\sim}$

$+++1$

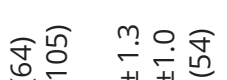

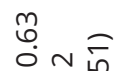

iो

ஸi்

ơ

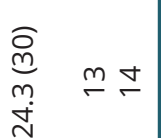

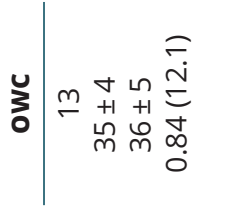

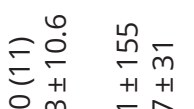

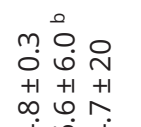

产紊

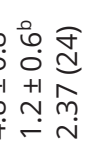

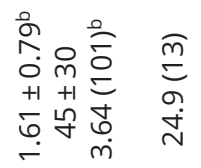

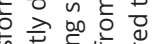

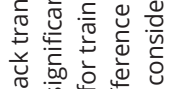

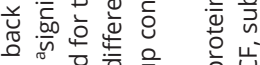

势

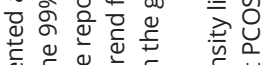

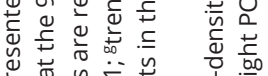

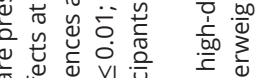

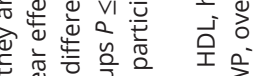

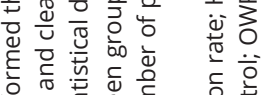

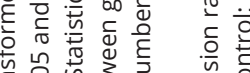

v

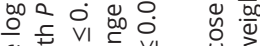

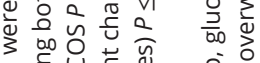

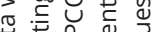

है

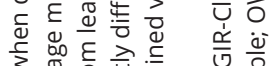

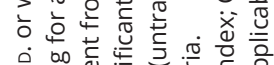

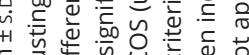

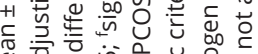

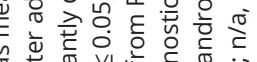

管

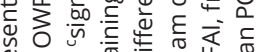

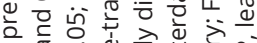

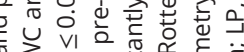

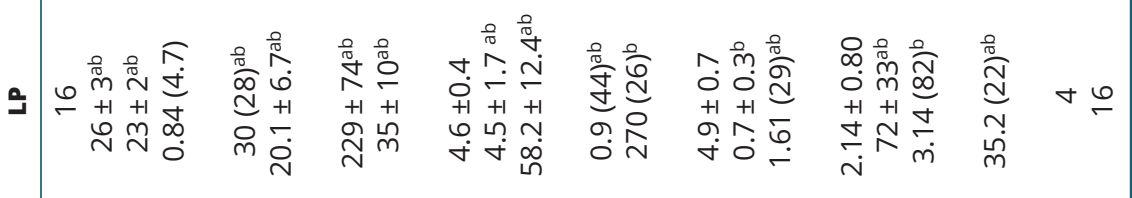

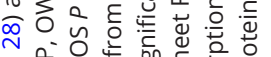

बे

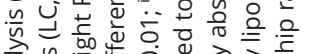

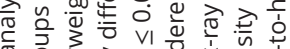

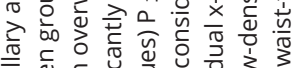

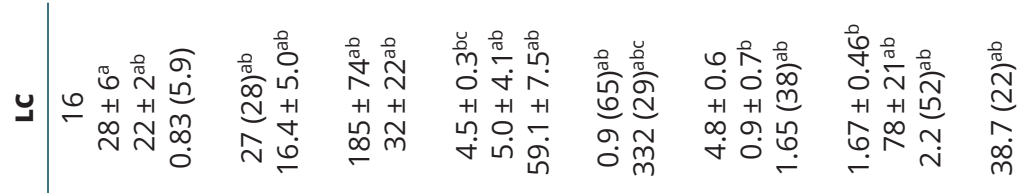

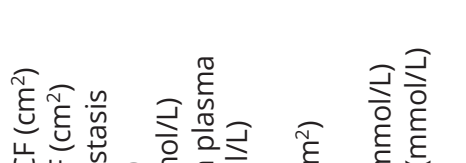

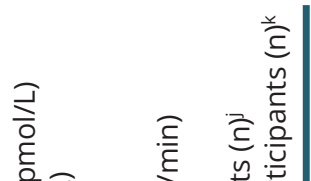

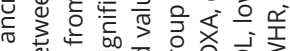

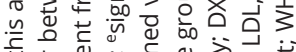

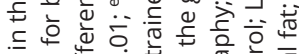

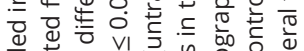

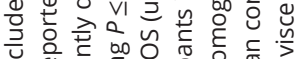

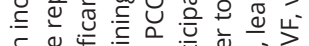




\section{Muscle protein extraction and Western} blot analyses

Equal quantities of protein, extracted as previously reported $(32,33,34)$, were resolved by SDS-PAGE (Bio-Rad, Criterion TGX Gels), transferred to a PVDF membranes (Bio-Rad, Turbo-Blot) using optimised protocols, blocked with TBST (10 mM Tris; 10\% Tween 20) containing $5 \%$ skim milk, washed 4 times for 5 mins in TBST and immunoblotted overnight at $4^{\circ} \mathrm{C}$ with primary antibodies $(32,33,34)$ targeting total and phospho-proteins including glucose transporter 4 (GLUT4), insulin receptor (IR), insulin receptor substrate 1 (IRS-1), protein kinase B/Akt, Akt substrate $160 \mathrm{kDA}$ (AS160), typical and atypical phospho-protein kinase $\mathrm{C}(\mathrm{PKC} / \theta$; $\mathrm{PKC} \lambda / \zeta)$, mechanistic target of rapamycin (mTOR), glycogen synthase kinase $3 \alpha$ (GSK) and glyceraldehyde phosphate dehydrogenase (GAPDH) as the loading control (Supplementary Table 1, see section on supplementary materials given at the end of this article). After washing and incubation with horseradish peroxidase-conjugated secondary antibody (Perkin Elmer) in 5\% skim milk and TBST, the immune-reactive proteins were detected with enhanced chemiluminescence (Amersham Biosciences) on the Versadoc MP4000 (BioRad) and quantified by densitometry (Quantity-One; BioRad). All phospho-protein data were normalised to their total protein, unless otherwise indicated (Figs 2, 4 and Supplementary Figs 1,2) to control for loading variability.

\section{RNA extraction and TGF $\beta$ network/tissue fibrosis gene expression analysis}

Total RNA was isolated from the muscle $(15-20 \mathrm{mg})$ using TRIzol and cleaned up with RNeasy Total RNA Kit columns (Qiagen). The total RNA content and purity were established by measuring absorbance at 260 and $280 \mathrm{~nm}$ (NanoDrop; Eppendorf). Ten micrograms of each RNA sample were then DNAse treated using DNase 1 (Thermo Fisher Scientific) described in detail in (35).

Relative gene expression was quantified by realtime PCR using the Qiagen RT2 custom profiler array for fibrosis pathway-related genes. $100 \mathrm{ng}$ of DNAse-treated RNA was used for cDNA, diluted 1 in 10 and amplified for 14 genes plus 2 housekeeping genes. cDNA was generated according to manufacturer's guidelines with modifications (35) using $40 \mu \mathrm{L}$ of Superscript RT III (Thermo Fisher Scientific). Custom array primers were designed against the human mRNA sequences for the corresponding genes in the Ref Seq database (Supplementary Table 2).

All reactions were performed according to the SybrGreen $^{\mathrm{TM}}$ cycle threshold (Ct) method using a Biorad CFX
384 real-time PCR detection. Thermocycling conditions for the PCR included $10 \mathrm{~min}$ at $95^{\circ} \mathrm{C}$ followed by 40 cycles of $15 \mathrm{~s}$ at $95^{\circ} \mathrm{C}$ and $1 \mathrm{~min}$ at $60^{\circ} \mathrm{C}$. Melt curve analysis from 72 to $95^{\circ} \mathrm{C}\left(5 \mathrm{~s}\right.$ per $\left.{ }^{\circ} \mathrm{C}\right)$ was performed to ensure a single defined peak for each amplified product. Comparative $\mathrm{Ct}$ calculations for the gene expression were performed by subtracting the mean GAPDH and ACTB Ct values from $\mathrm{Ct}$ values of the gene of interest to derive a $\Delta \mathrm{Ct}$ value. The expression of the genes was calculated according to the formula: $2^{-\Delta \mathrm{Ct}}$.

\section{Statistical analysis}

All statistical analyses were conducted using mixed modelling procedures (PROC MIXED) in Statistical Analysis System (version 9.4, SAS Institute). Data, unless otherwise stated, were log transformed before analysis to overcome heteroscedastic issues and presented as a back-transformed mean with standard deviation (s.D.) as a coefficient of variation (CV; \%). For the cross-sectional study separate models were generated to compare differences in variables between groups including participant characteristics, gene expression, where the fixed effects in the model estimated the main effects of PCOS (PCOS/Control) and obesity (BMI - Lean $(<27$ $\left.\mathrm{kg} / \mathrm{m}^{2}\right)$ and overweight $\left(>27 \mathrm{~kg} / \mathrm{m}^{2}\right)$ as per (9)) status as nominal variables and the modifying effect of age a linear numeric variable. To estimate the main effects of PCOS and BMI on the fold change (with an s.D. as expressed CV \%) in normalised protein phosphorylation induced by $30 \mathrm{~min}$ of insulin infusion the fixed effects were again PCOS and BMI status as nominal variables interacted with baseline phosphorylation levels, age and change plasma insulin concentrations (linear numeric variables). For the exercise training substudy, a similar approach was adopted and the main effects of PCOS (PCOS/Control) and training status (untrained vs trained) on participant characteristics, gene expression, baseline protein abundance and insulin-induced changes phospho-protein abundance were determined with the fixed effects in the model where PCOS and training status as nominal variables and interacted with the dependent variables baseline value. All models estimated between group differences of variables or changes in variables as a percentage and presented with 99\% confidence intervals (99\% CI). Pearson correlations (PROC CORR; SAS v9.4) were used explore relations between GIR and a select number of variables. Significance was accepted when $P<0.05$. As an a priori decision, we ran a parallel analysis on our mixed 
A

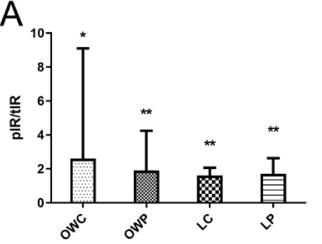

D

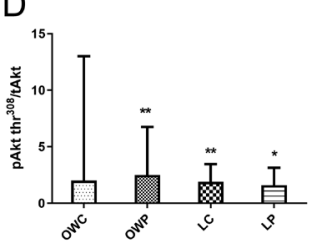

G

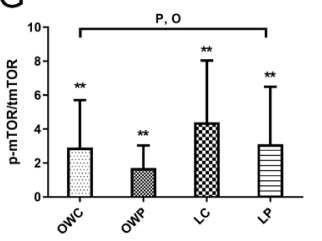

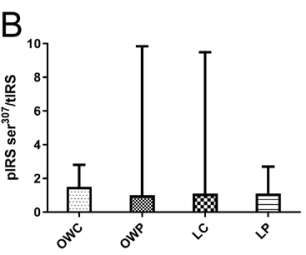

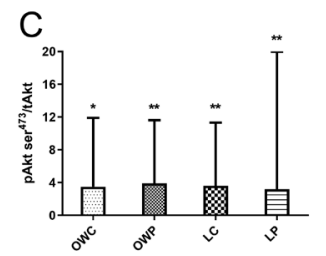

E
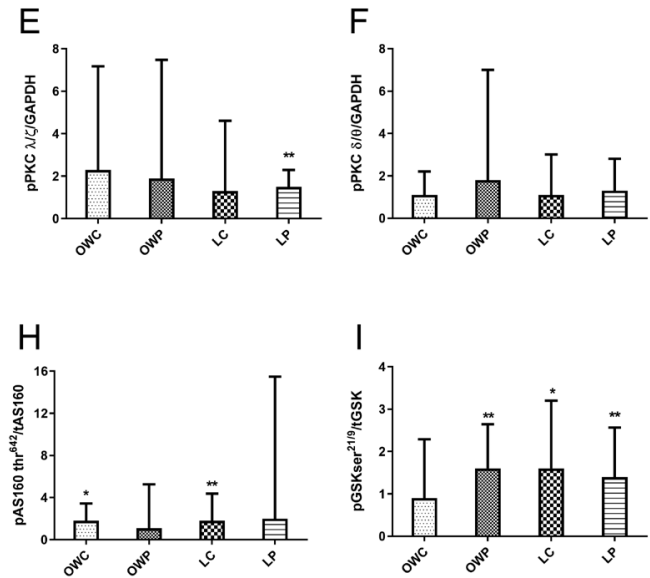

Ins

OWC OWP LC LP

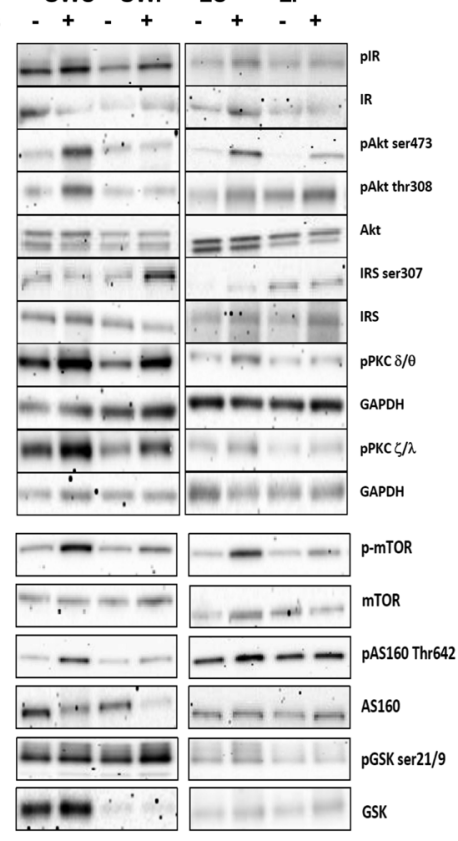

Figure 2

Normalised fold change of insulin stimulated (30 min) phosphorylation of key proteins in the insulin signalling pathway and insulin signalling pathway regulators. (A) insulin receptor (IR), (B) insulin receptor substrate 1 serine 307 (IRS1), (C) protein kinase B/Akt serine 473 (Akt), (D) Akt threonine 308 , (E) atypical protein kinase B (PKC $(\zeta / \lambda)$ ), (F) typical PKC $(\delta / \theta),(\mathrm{G})$ mechanistic target of rapamysin (mTOR), (H) Akt substrate 160 kDa $(A S 160)$, (I) glycogen synthase kinase ser 21/9. Covariate adjusted statistical difference reported as: *significant fold increase with insulin stimulation $P<0.05$ (and clear effect at $99 \% \mathrm{CL}$ ), ** significant fold increase with insulin stimulation $P<0.01$ (and clear effect at $99 \% \mathrm{CL}$ ), ${ }^{\mathrm{P}}$ significant impact of PCOS $P<0.05$ (and clear effect at

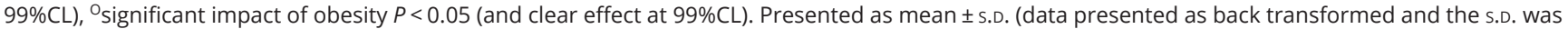
derived as a coefficient of variation (\%)), $P<0.05$.

model outcomes using a Bayesian method that has no or minimally informed prior or belief about the effects or standard deviations or magnitude-based inferences $(10,36)$. This method allowed us to make probabilistic assertions about the true magnitudes of effects using the non-clinical version of magnitude-based inference, according to which an effect was deemed unclear if the 99\% CI spanned substantial positive and negative values of the smallest worthwhile effect ( 0.2 times between participant S.D.); all other effects were deemed clear and assigned the magnitude of the analysed effect, along with the chances that the effect was substantial and/or trivial (36). The magnitude-based inference component of our combined statistical approach was used to provide a standardised effect size $(<0.2$, trivial; $0.2-0.6$, small; $0.6-1.2$ moderate, $1.2-2$ large) and to account for inflation of error arising from the large number comparisons investigated. We only reported effects that met our significance criteria $(P<0.05)$ and were deemed to have a clear standardised-effect by magnitude-based inference for the $99 \% \mathrm{CI}$ of the analysed effect.

\section{Results}

All clinical data differentiating the different groups of women from the subset of participants used in this analysis and the beneficial impact of exercise training are detailed in Table 1. Between-group differences for insulin-stimulated phosphorylation signalling protein abundance and gene expression are reported as fold changes with $99 \%$ CI that includes the adjustments for the appropriate covariates.

\section{Insulin signalling}

Abundance of key phospho-proteins in the insulin signalling pathway across the distal and proximal components, as well as the insulin signalling pathway regulators were analysed across the four groups of women to identify early insulin signalling defects in skeletal muscle that align with PCOS-specific insulin resistance (Fig. 2 and Supplementary Fig. 1). Overall $30 \mathrm{~min}$ of insulin infusion stimulated phosphorylation of the signalling proteins across all groups where

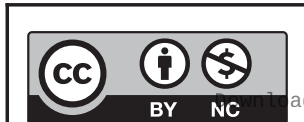

This work is licensed under a Creative Commons Attribution-NonCommercial 4.0 International License. ded from Bioscientifica.com at 04/26/2023 09:24:23AM 
IR-tyr ${ }^{1162 / 1163}$, Akt-ser ${ }^{473}$, Akt-thr ${ }^{308}$, mTOR, AS160-thr ${ }^{642}$ and GSK-ser ${ }^{21 / 9}$ underwent significant/meaningful increases $(P<0.05$ and large effects) ranging from 1.6 to 4.4 -fold (Fig. 2). Only one signalling protein, mTOR demonstrated altered phosphorylation, after adjustments for covariates, where obesity and PCOS reduced phosphorylation. Specifically, PCOS resulted in a moderate 0.6 fold ((99\% CI 0.4-0.8), $P=0.01$ ) reduction of phosho-mTOR compared to non-PCOS women. Similarly, obesity also induced a moderate 0.6 fold ((99\% CI 0.4-0.9) P=0.019) compared to lean women. Taken together these data suggest altered insulin-sensitive metabolic signalling distal to Akt which may impact the translocation of the glucose transporter protein GLUT4 and therefore glucose uptake into muscles. We found no differences in protein expression of GLUT 4 between the groups (data not shown).

\section{Gene expression for tissue fibrosis}

The relative gene expression of $C O L 1 A 2, C O L 3 A 1, D C N$, IGF1, LOX, LTBP1, TGFB2 and TGFBR2 was impacted by both obesity and/or PCOS status with small to moderate between-group differences (Fig. 3) suggesting aberrant signalling via the TGF $\beta$ ligand signalling network, establishing a pro-fibrotic gene program. Specifically, COL1A2 and $3 A 1$ were 2.14 fold (99\% CI: 1.8, 2.4; $P=0.001)$ and 2.12 fold (99\% CI: 1.7, 2.4\%; $P=0.005$ ) higher in OWP compared to OWC. The OWC group had higher (1.83 fold; $P<0.05)$ expression of both COL1A2 and $3 A 1$ compared to LC. The LTBP1 gene expression was highest in the overweight groups, with OWP having significantly higher (0.75 fold, 99\% CI: 0.6, 0.9; $P=0.008$ ) expression than LC. For DCN (1.94 fold, 99\% CI: 1.5, 2.2; $P=0.005$ ) and $\operatorname{LOX}$ (2.44 fold 99\% CI: 1.7, 2.7; $P=0.021$ ) the OWP group had higher gene expression than OWC. While $D C N$ in LC was lower (0.66 fold, $P=0.031$ ) and $L O X$ was 2.98 fold higher $(P=0.025)$ than OWC. The TGF $\beta$ signalling-related gene expression was higher in the OWP group where TGFB2 and TGFBR2 expression were 1.8 fold (99\% CI: $1.5,2.0 ; P=0.0009)$ and 1.76 fold (99\% CI: 1.4 , 2.0, $P=0.004$ ) higher in OWP compared to LC respectively. TGFBR2 gene expression was 1.8 fold higher in OWP vs OWC $(P=0.005)$. In contrast, IGF1 gene expression was lowest in OWC being 2.5 fold (99\% CI: 1.6, 4.1; $P=0.006)$ compared to LC, with OWC also being lower (0.48 fold 99\% CI: 0.3, 0.8; $P=0.026)$ than OWP.

Overall GIR negatively correlated with body composition (BMI; android, gynoid and visceral fat; and DXA-derived fat free mass and appendicular muscle mass) and FAI (Supplementary Table 3). In contrast, GIR was positively correlated with aerobic fitness and SHBG concentrations (Supplementary Table 3). These overall associations were due to the stronger correlations observed in the women with PCOS compared to controls across the BMI categories. GIR was also positively correlated to the fold change in insulin-stimulated (30 $\mathrm{min}$ ) phosphomTOR $\left(r^{2}=0.43, P=0.02\right)$ in the PCOS group only and negatively correlated to TGFBR2 gene expression overall $\left(r^{2}=-0.37, P=0.03\right)$.

\section{Impact of exercise}

In the women (with overweight/obesity) who participated in the 12-week treadmill exercise intervention a number of changes in clinical features (Table 1), insulin signalling (Fig. 4 and Supplementary Fig. 2) and TGF $\beta$ signalling network gene expression (Fig. 5) were observed. Traininginduced differential responses to $30 \mathrm{~min}$ of insulin stimulation, where only phospho-Aktser ${ }^{473}$ and phosphoGSKser $^{219}$ were impacted differently by the training intervention. OWP demonstrated a small attenuation in phosphorylation of phospho-Aktser ${ }^{473}(0.45$ fold 99\% CI: $0.3, \quad 0.8 ; \quad P=0.019)$ and phospho-GSKser ${ }^{219}$ (0.48 fold 99\% CI: 03, 0.8; $P=0.027$ ) compared to OWC women, respectively. Surprisingly, very few phosphoproteins demonstrated clear with-in group impacts of training. Specifically, training resulted in a large augmentation of insulin-stimulated phospho-AS160 of 1.82 fold (99\% CI: 1.2, 2.7; $P=0.025$ ) from pre- to post-training in OWP. On the other hand, training resulted in a small attenuation of phospho-GSKser219 (0.58 fold 99\% CI: $0.4,07 ; P=0.006)$ from pre- to post-training in OWP group.

We also reported small to moderate differential training-induced changes in relative gene expression (Fig. 5) of genes for ECM deposition, COL1A2, COL3A1, $D C N$ and $L O X$, which only occurred in OWP women. COL1A2 gene expression increased by 1.65 fold (99\% CI: $1.2,2.2 ; P=0.02$ ) from pre- to post-training in the OWP women. Similarly exercise training induced COL $3 A 1$ and $L O X$ gene expression increases of 1.94 fold (99\% CI: 1.1, 3.4; $P=0.05$ ) and 1.95 fold (99\% CI: $1.3,3.0 ; P=0.03$ ), respectively.

The exercise-induced changes in GIR did not correlate with any fold changes in insulin-induced increases/ decreases in protein phosphorylation nor changes in gene expression (Supplementary Table 4) in any group. However, changes in FAI were negatively correlated with the training-induced changes in GIR $\left(r^{2}=-0.74 ; P=0.04\right)$ in women with PCOS, indicating increased insulin sensitivity was associated with a decreased FAI. 

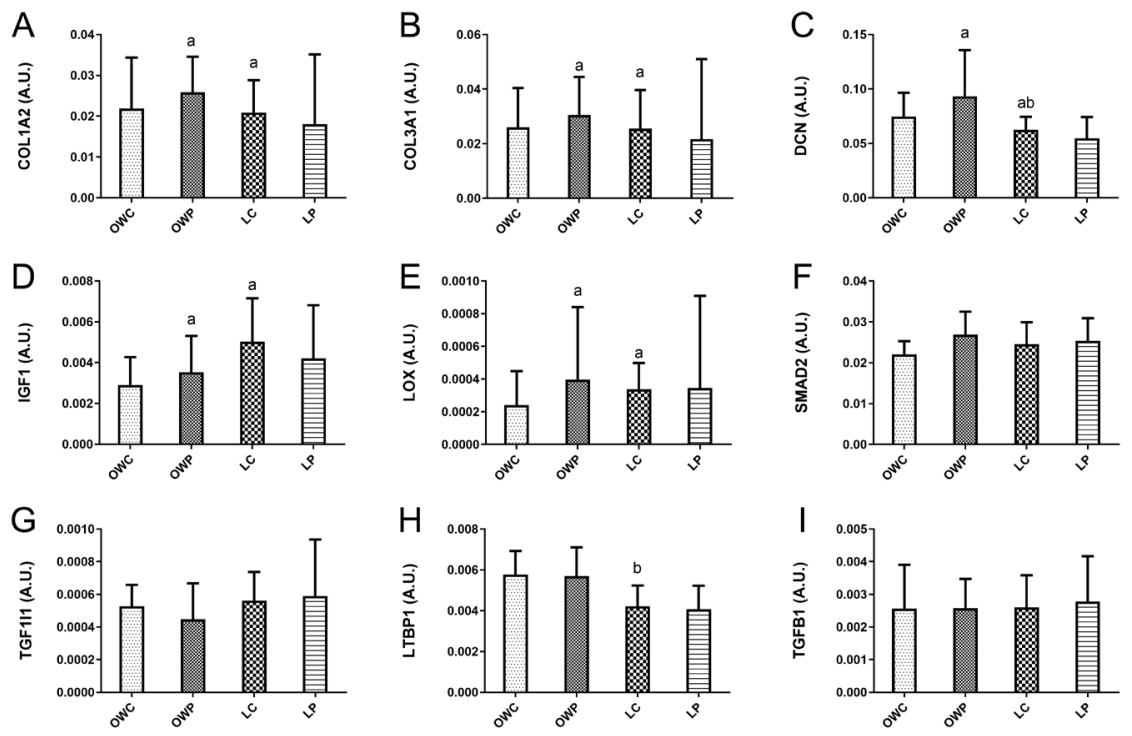

\section{Figure 3}

Relative gene expression of the tissue fibrosis (TGF $\beta$ ) pathway. Gene expression was normalised to the mean of GAPDH and ACTB (the housekeeping genes) expression. (A) COL1A2, (B) COL3A1, (C) DCN, (D) IGF1, (E) LOX, (F) SMAD2, (G) TGF1/1, (H) LTBP1, (I) TGFB1, (J) TGFB2, (K) TGFB3, (L) TGFBR2. These data are from a subset of women $(n=59)$ (9). Covariate adjusted statistical
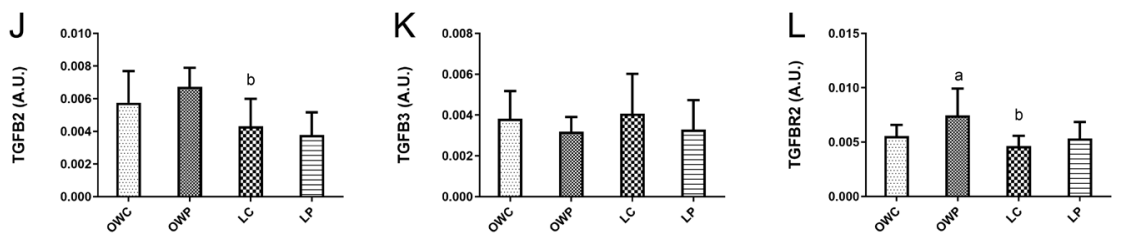
difference reported: a- significantly different from overweight control $P<0.05$ (and clear effect at $99 \% \mathrm{CL}$ ), b- significantly different from overweight PCOS $P<0.05$ (and clear effect at $99 \% C L$ ). Data are presented as mean \pm S.D. (data presented as back transformed and the S.D. was derived as a coefficient of variation (\%)).

A

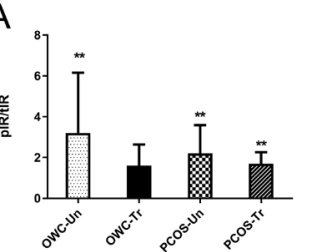

B
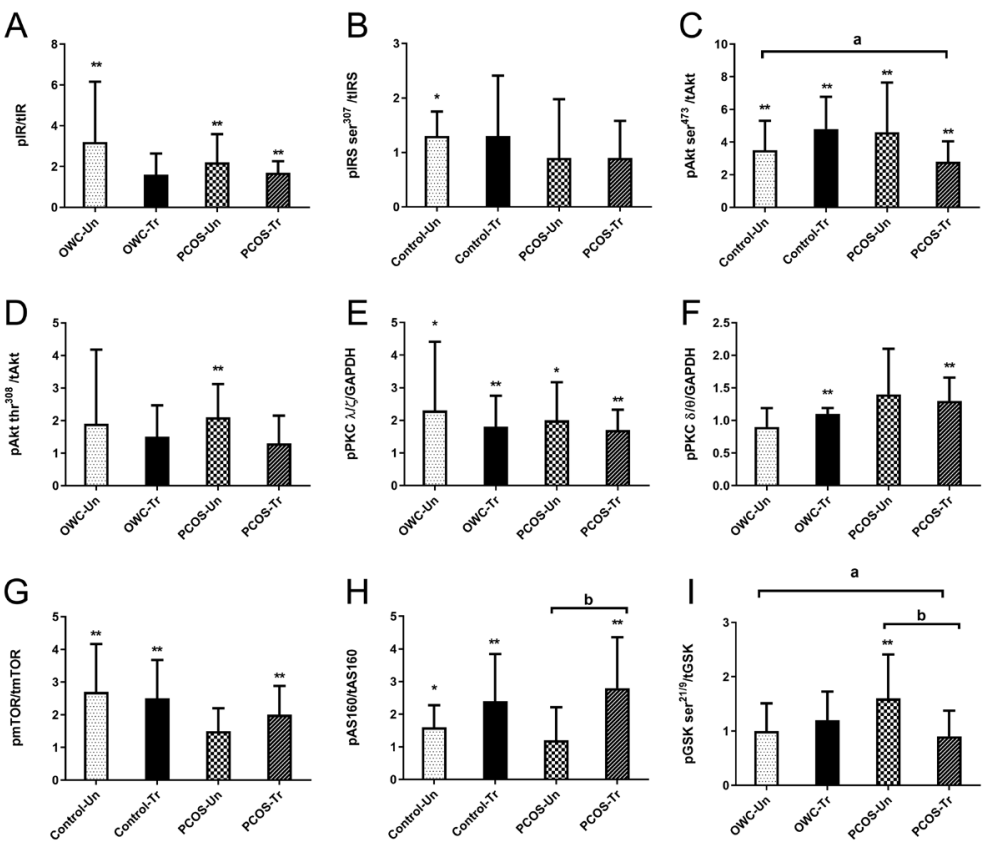

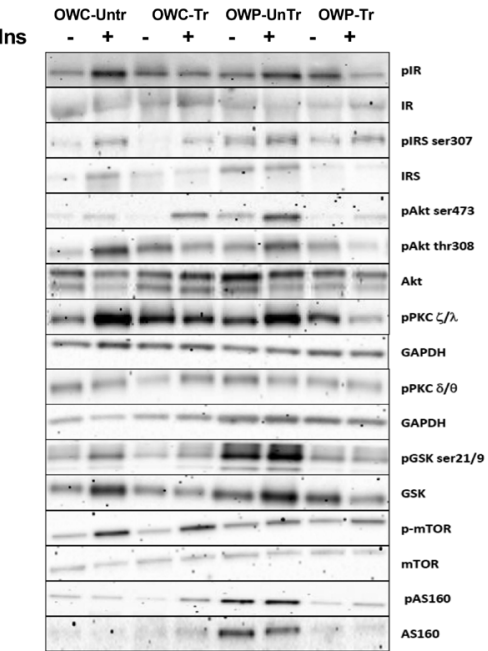

Figure 4

Normalised fold change of insulin stimulated (30 min) phosphorylation of key proteins in the insulin signalling pathway before and after 12 weeks of intensified aerobic exercise training in overweight women with and with PCOS. (A) insulin receptor (IR), (B) insulin receptor substrate 1 serine 307 (IRS1), (C) protein kinase B/Akt serine 473 (Akt), (D) Akt threonine 308, (E) atypical protein kinase B (PKC ( $\zeta / \lambda)$ ), (F) typical PKC ( $\delta / \theta)$, (G) mechanistic target of rapamysin (mTOR), (H) Akt substrate $160 \mathrm{kDa}$ (AS160), (I) glycogen synthase kinase ser 21/9. These data are from a subset of women ( $n=8$ PCOS, $n=8$ control) from $(28,29)$. Covariate adjusted statistical difference reported as: * significant fold increase with insulin stimulation $P<0.05$ (and clear effect at

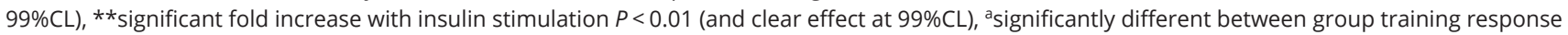
$P<0.05$ (and clear effect at $99 \% \mathrm{CL}$ ), bsignificantly with in group training response $P<0.05$ (and clear effect at $99 \% C L$ ). Presented as mean \pm S.D. (data presented as back transformed and the S.D. was derived as a coefficient of variation (\%)).

https://ec.bioscientifica.com https://doi.org/10.1530/EC-19-0551 (c) 2020 The authors Published by Bioscientifica Ltd

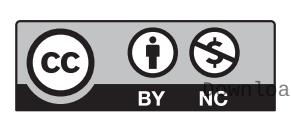

This work is licensed under a Creative Commons Attribution-NonCommercial 4.0 International License. ded from Bioscientifica.com at $04 / 26 / 2023$ 09:24:23AM 


\section{Discussion}

Taking a novel sampling approach, this study demonstrated dysfunction in insulin signalling after 30 min of insulin infusion during an insulin clamp in women with PCOS across a range of BMIs. This dysfunction was distal to Akt/PKB and associated with end-clamp insulin sensitivity. Specifically, reduced insulin stimulated phospho-mTOR was associated with PCOS and obesity status. A 12-week exercise intervention improved, but did not rescue insulin sensitivity in OWP compared to OWC women and these improvements were accompanied by augmented phospho-AS160 and phospho-mTOR (trend) but attenuated phospho-Akt-ser ${ }^{473}$ and phoshoGSKser ${ }^{21 / 9}$ in PCOS. We found genes in the TGF $\beta$ regulated tissue fibrosis pathway that encode ECM components (COL1A2, COL3A1), enzymes in the collagen deposition and assembly ( $L O X, D C N)$, ligands (TGFB2) and their receptor were elevated in OWP. After the 12-week training intervention COL1A2, COL3A1, DCN and LOX were differentially regulated in the OWP compared to OWC women. Overall women with PCOS, especially the OWP showed a gene expression pattern conducive to greater TGF $\beta$ ligand-driven ECM or fibrosis, even after the exercise training intervention.
Defects in insulin signalling in skeletal muscle are well documented for insulin-resistant conditions (17), including PCOS $(13,37)$. Our data significantly expands this work exploring possible defects in both proximal and distal components of this pathway in lean and overweight controls and women with PCOS. In agreement with the literature $(13,17,37)$ our data demonstrated an obesity-induced defect in the insulin receptor activation of signalling, due to differential phosphorylation of tyr ${ }^{1162 / 1163}$ between the lean and overweight groups with no impact of PCOS status. When obesity (BMI) and prevailing insulin concentrations were accounted for, the obesity-driven differences were negated and the lack of impact of PCOS status remained (Fig. 2), as previously reported $(13,37)$. Our data allowed us to explore the hypothesis of Diamanti-Kandarakis and Dunaif (13) where there may be a PCOS-specific serine kinase targeting IRS1/2. mTOR could be this kinase $(38,39)$, however, our in vivo data contrast with this hypothesis as no insulinstimulated change was detected in any group. These data suggest that signalling defects are more likely distal to the IR and IRS1/2 in skeletal muscle of women with PCOS.

A key finding of this study, was that our in vivo data show reduced phosphorylation of mTOR occurred in PCOS-specific manner and implicates this protein
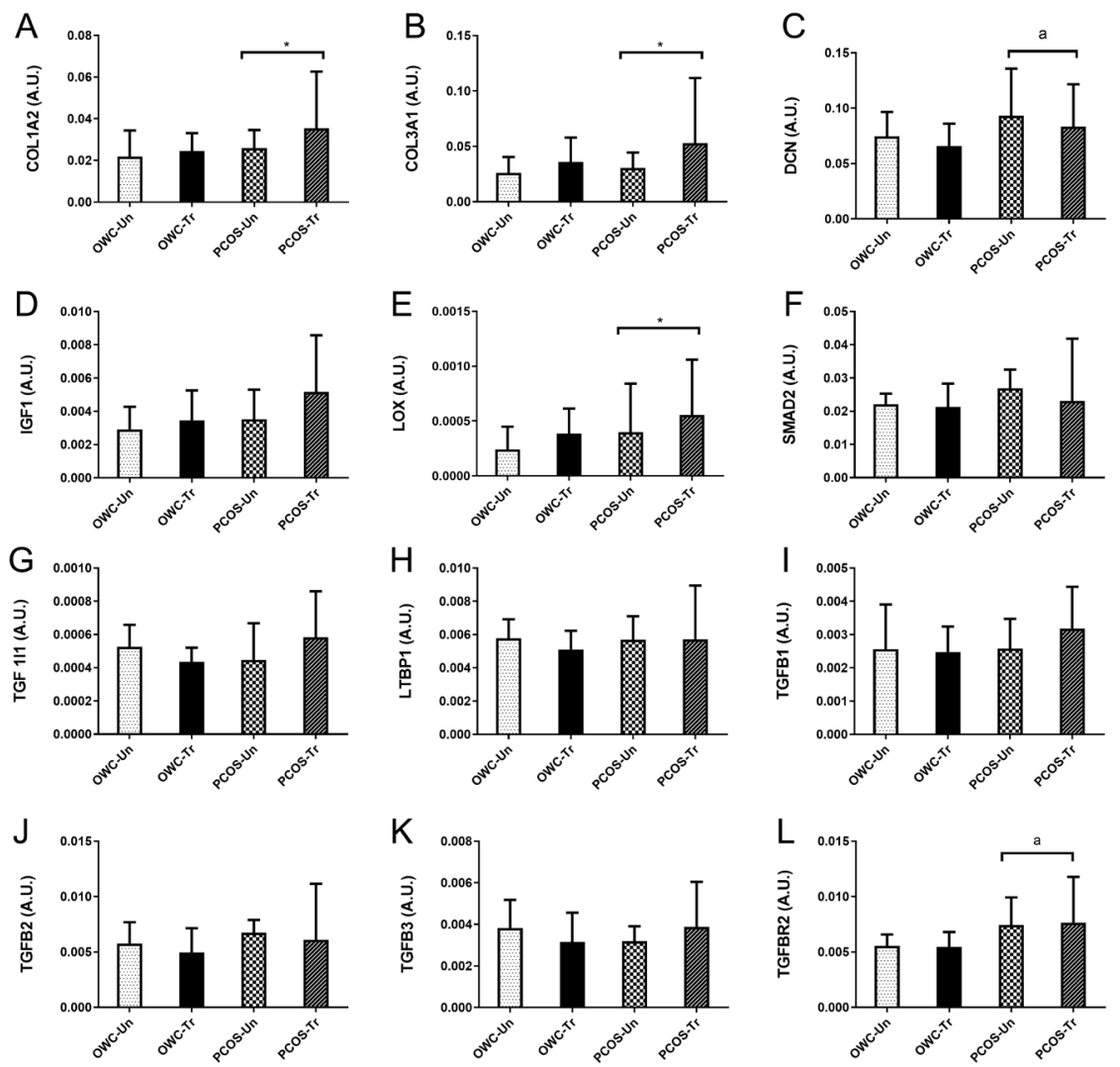

\section{Figure 5}

Training response of relative gene expression in the tissue fibrosis (TGF $\beta$ ) pathway for women with and without PCOS after 12 weeks of intensified exercise training. (A) COL1A2, (B) COL3A1, (C) DCN, (D) IGF1, (E) LOX, (F) SMAD2, (G) TGF1/1, (H) LTBP1, (I) TGFB1, (I) TGFB2, (K) TGFB3, (L) TGFBR2. These data are from a subset of women ( $n=8$ PCOS, $n=8$ control) from $(28,29)$. Presented as

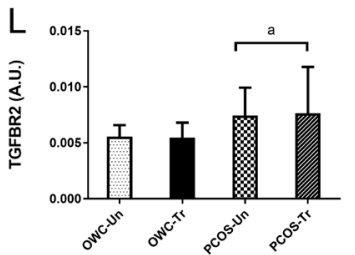

mean \pm S.D. (data presented as back transformed and the S.D. was derived as a coefficient of variation (\%)). Covariate adjusted statistical difference reported: *significant within group training effect $P<0.05$ (and clear effect at $99 \% \mathrm{CL}$ ), ${ }^{a}$ significant difference between OWC and OWP $P<0.05$ (and clear effect at $99 \% \mathrm{CL}$ ). https://ec.bioscientifica.com https://doi.org/10.1530/EC-19-0551 (c) 2020 The authors Published by Bioscientifica Ltd

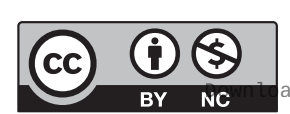

This work is licensed under a Creative Commons Attribution-NonCommercial 4.0 International License. ded from Bioscientifica.com at 04/26/2023 09:24:23AM via free access 
complex as a mechanism of insulin resistance in PCOS (Supplementary Table 3). These data differ from a recent study (21) investigating insulin signalling defects in lean hyperandrogenic women with PCOS, where defects in adenosine monophosphate kinase (AMPK) and pyruvate dehydrogenase (PDH) activity explain insulin resistance. This work was not without limitations (e.g. lean women only, no fitness assessments (8)) and did not consider mTOR, the alternate metabolic signalling pathway. mTOR signalling via its complex mTORC1 $(\mathrm{mTOR}+$ raptor $)$ is associated with nutrition-regulated anabolic processes in skeletal muscle (40). More recently the mTORC2 (mTOR+rictor) has been linked to insulin resistance in skeletal muscle in vitro and animal models in the presence of reduced phospho-Akt ser ${ }^{473}$, altered intracellular glucose handling, irrespective of levels of phospho-Akt-thr ${ }^{308}$ and GLUT4 vesical trafficking (39). The women with PCOS from the exercise training subgroup had improved, but not rescued mTOR signalling responses to insulin, which did not correlate with training-induced changes in GIR (Supplementary Table 4). As we were unable to quantify the different mTOR complexes, due to tissue availability, we could not establish if mTORC2 was associated with this PCOSspecific reduction in insulin signalling and sensitivity. More research is needed to understand the PCOS-specific mTOR downregulation and its role in the intrinsic insulin resistance in skeletal muscle.

AS160, GSK3, typical PKC $(\delta / \theta)$ and atypical PKC $(\lambda / \xi)$ insulin-stimulated phosphorylation were surprisingly similar between groups but there were trends for obesity to reduce signalling. GLUT4 is considered important in skeletal muscle insulin and exercise stimulated glucose uptake (26) where our data for protein expression of GLUT4 (data not shown) surprisingly found no differences between the four groups of women. While these data align with previous work suggesting comparable levels of GLUT4 between women with and without PCOS (41), our methodology (centrifuged muscle lysate and heating prior to gel separation) may mask/underestimate any true differences and effects. The 12-week exercise intervention clearly impacted the dysfunctional phosphorylation of three signalling proteins. Specifically, phospho-AS160, a key protein in Glut4 vesicle translocation (42), was improved in the OWP women, aligning with other training studies (in males (32)). On the other hand phosphoAkt and -GSK3 (regulation of glycogen synthesis (38)) demonstrated contradictory reductions post-training in the OWP women. This was unexpected, especially the reduced phospho-Akt; however, there is the non-linearity of signalling via Akt (43) and thus limiting its impact on any training induced improvements of GIR in OWP. The training intervention did not induce significant changes in the other signalling proteins, each having a vital role in regulating insulin-stimulated glucose uptake either as downstream substrates of Akt or independently including regulation of Glut4 vesicle translocation (Atypical PKC $(\lambda / \xi)(44))$ and integration lipid availability to reduce glucose uptake (typical PKC $(\delta / \theta)(45,46))$. In summary, our data suggest that the reduced early activation of proteins below Akt are linked to PCOS-specific insulin resistance. This is despite the alteration but not normalisation of phosphorylation defects by training. Overall, these data and that of others $(9,10)$ suggests insulin signalling defects in skeletal muscle account for some insulin resistance, but additional molecular mechanisms are responsible for the PCOS-specific insulin resistance and its synergy with obesity.

There is emerging data suggesting that at least TGF $\beta 2$ is an exercise induced adipokine that promotes insulin sensitivity (25). However, these data are currently biased to male samples and mainly rodent physiology but they do further support the notion that TGF $\beta$ pathways are important for insulin sensitivity and response to exercise. Human data supporting $(23,24)$ induction of insulin resistance provide a direct role of TGF $\beta$ signalling, via the SMAD proteins in skeletal muscle glucose uptake. In the context of the aetiology of PCOS, our new hypothesis (22) of TGF $\beta$ ligand mediated excess stromal deposition or fibrosis, may apply beyond the ovary to metabolic tissues like skeletal muscle in women with PCOS, predisposing them to insulin resistance. Dysfunctional TGF $\beta$ or TGF $\beta$ superfamily ligand signalling may be involved as anti-müllerian hormone (AMH) (47) and TGF $\beta 1$ (48) are elevated in women with PCOS. These ligands act via their respective receptors to activate the SMAD signalling proteins that are not only negative regulators of Akt (49) and mTOR (24), but are key signals in ECM deposition. Thus, this pathway is a plausible contributor to dysfunctional insulin signalling and reduced sensitivity in PCOS. Our gene expression data of elevated collagen, ECM deposition enzymes and TGF $\beta 2 \mathrm{R}$ gene expression (pro-fibrotic gene profile), elevated ligands (AMH (47) and TGF $\beta 1$ (48)) and our previously reported high tissue density (elevated Hounsfield units) in thigh skeletal muscle from CT analysis (29), support the notion that TGF $\beta$ ligand signalling and tissue fibrosis may be involved in PCOS-specific skeletal muscle insulin resistance (8). This may occur not only via SMAD protein signalling interfering with Akt

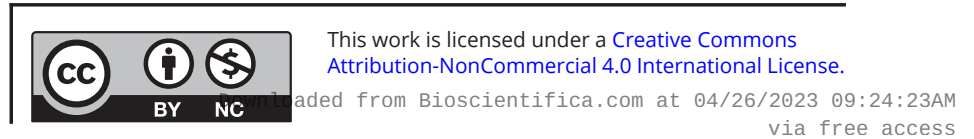


and/or mTOR signalling, but also via increased ECM possibly limiting insulin and glucose movement across the interstitial space. Interestingly, exercise training had no effect on this network of genes except LOX, COL1A2 and $3 A 1$ where expression was augmented. This provides a possible mechanism for resistance to insulin sensitising therapies in PCOS, which aligns with other research (23) and warrants further investigation. Therefore, our data support our hypothesis (22) and allows us to expand our understanding of insulin resistance in skeletal muscle in PCOS and its attenuated response to therapy. We now propose that the TGF $\beta$ ligand signalling via SMAD-mTOR/SMAD-Akt pathways plus tissue fibrosis is mechanistically involved in PCOS-specific insulin resistance, its synergy with obesity (Fig. 6) and possible resistance to therapy.

Our study limitations included a small sample size $(9,28,29)$ due to the invasive procedures used to obtain tissue samples. As this was an ancillary analysis tissue availability was limited (additional analysis via immunoblotting of TGF $\beta$ signalling) and not collected to for immunohistochemistry. We acknowledge that the sample size was limited for the exercise arm of the study, which may have limited power to detect exerciseinduced alterations in fibrosis in the OWC group. Alternatively, we could also speculate that perhaps on OWC exercise does not re-model the ECM unlike the OWP. However, the strengths of this work were the use of gold-standard methods to assess insulin sensitivity in a community-recruited, well-characterised population of lean and overweight women with or without PCOS. We cannot rule out contributions of differential body composition and other systemic factors (Supplementary Tables 3 and 4) to insulin resistance in women with PCOS. Specifically, FAI index correlated strongly (negatively) with end clamp GIR in women with PCOS but not controls, but were no longer significant when LP and OWP were considered separately $\left(r^{2} \sim-0.40\right.$, $P>0.05)$. Additionally, exercise-induced reduction in FAI correlated strongly with the increases in GIR for the sub-group of PCOS women. These data suggest a role of hyperandrogenism in PCOS-specific IR. However, FAI did not correlate with any insulin signalling or TGF $\beta$ and tissue fibrosis gene expression data in this study. FAI is a calculated variable dependant on SHBG concentrations, which are impacted by insulin resistance (50). Taken together with most literature $(10,13)$ this study could not establish the role of hyperandrogenism in causing insulin resistance in PCOS via peripheral tissue insulin signalling and fibrosis.

\section{Conclusions}

Our data provide new insights into PCOS-specific insulin resistance and the associated early signalling events in skeletal muscle highlighting a role for aberrant mTOR signalling. These data also support our hypothesis that TGF $\beta$ superfamily ligands, their signalling and tissue fibrosis are involved in PCOS-specific insulin resistance,

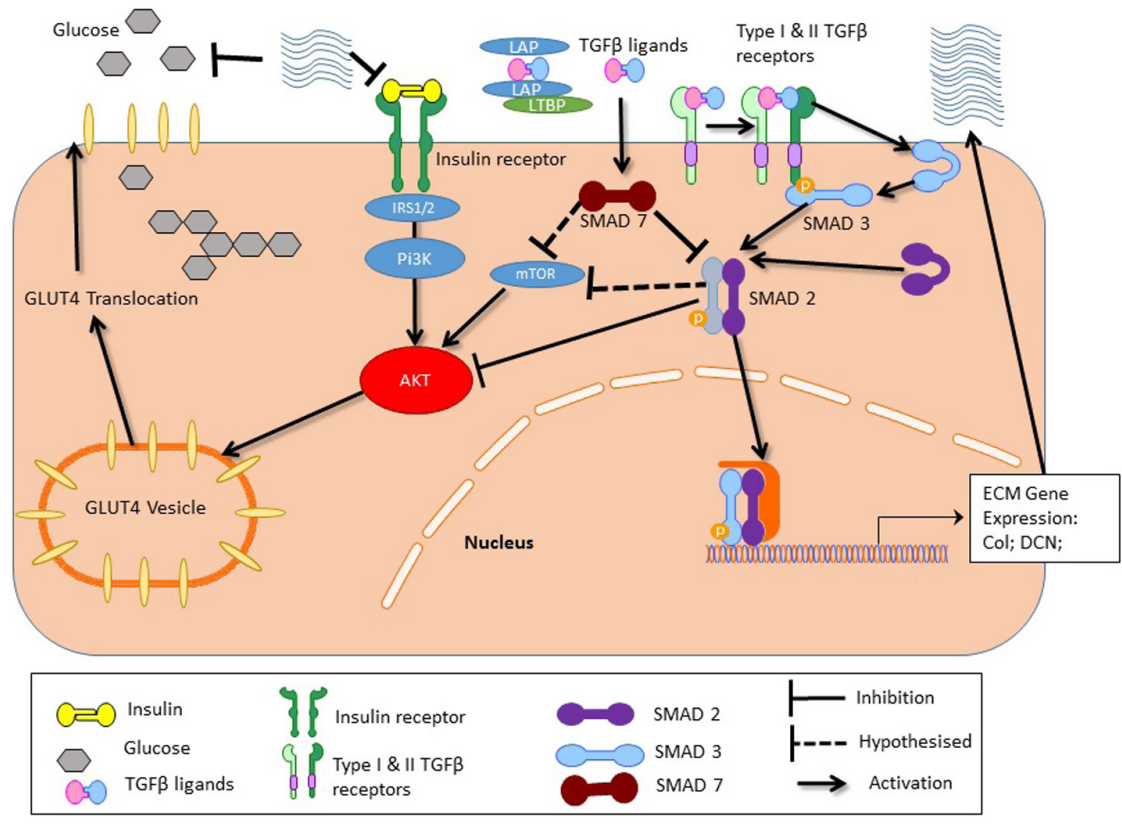

Figure 6

Hypothetical signalling pathway showing that dysfunctional TGF $\beta$ network signalling regulates tissue fibrosis and may play a role in this PCOS-specific insulin resistance and its limited response to exercise training. https://ec.bioscientifica.com https://doi.org/10.1530/EC-19-0551 (c) 2020 The authors Published by Bioscientifica Ltd

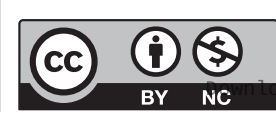

This work is licensed under a Creative Commons Attribution-NonCommercial 4.0 International License. ded from Bioscientifica.com at 04/26/2023 09:24:23AM 
particularly driving the synergy between obesity and PCOS. Intensified aerobic exercise training did not restore insulin sensitivity, despite improving insulin stimulated signalling at Akt, AS160 and mTOR in overweight women with PCOS. There was no clear evidence to support a role for hyperandrogenism in peripheral tissue insulin resistance, in women with PCOS. Overall, additional human research (in vivo and in vitro), supported by appropriate animals studies, is warranted to elucidate the role of androgens, mTOR signalling, TGF $\beta$ ligand signalling networks and ECM deposition in PCOS-specific insulin resistance.

\section{Supplementary materials}

Supplementary data has been deposited in a public data share repository and is available at: https://figshare.com/articles/Supplementary_Material_ Molecular_Mechanisms_of_Insulin_Resistance_in_Skeletal_Muscle_of_ Women_with_PCOS/6726761.

\section{Declaration of interest}

N S, B S, B C and H T were awarded the NHMRC grant APP606553 (2010-2011), N S and R R were awarded an NHMRC grant APP1156329 (2019-2022), D H an Australia Postgraduate Scholarship. M G H and H T are NHMRC Research Fellows (APP1110701 and APP1042516). The other authors have nothing to disclose.

\section{Funding}

The study was funded by the National Health and Medical Research Council of Australia (NHMRC) project grant scheme grants APP606553 and APP1156329.

\section{Author contribution statement}

N S and H T made substantial contributions to conception and design, acquisition of data, analysis and interpretation of data; drafting the article or revising it critically for important intellectual content; final approval of the version to be published. A J, A M A, B S, B C, C H, D H, M G H, N H, R R and $S C$ made substantial contributions to acquisition of data, analysis and interpretation of data; drafting the article or revising it critically for important intellectual content; final approval of the version to be published.

\section{Acknowledgements}

The authors wish to acknowledge the passing of their esteemed colleague and friend Prof Nigel Stepto, 4 February 2020. The authors would like to thank Profs James D Cameron and Juleen R Zierath for their critical insights into study design and funding, Prof Will Hopkins for MBI statistics and SAS coding and Dr Rebecca Goldstein for assistance during the trials. Data sharing is available with de-identified raw data, statistical programs and analysis plans all available from authors on request.

\section{References}

1 Bozdag G, Mumusoglu S, Zengin D, Karabulut E \& Yildiz BO. The prevalence and phenotypic features of polycystic ovary syndrome: a systematic review and meta-analysis. Human Reproduction 201631 2841-2855. (https://doi.org/10.1093/humrep/dew218)
2 Moran LJ, Lombard CB, Lim S, Noakes M \& Teede HJ. Polycystic ovary syndrome and weight management. Women's Health 20106 271-283. (https://doi.org/10.2217/whe.09.89)

3 Kakoly NS, Khomami MB, Joham AE, Cooray SD, Misso ML, Norman RJ, Harrison CL, Ranasinha S, Teede HJ \& Moran LJ. Ethnicity, obesity and the prevalence of impaired glucose tolerance and type 2 diabetes in PCOS: a systematic review and metaregression. Human Reproduction Update 201824 455-467. (https://doi. org/10.1093/humupd/dmy007)

4 Lim SS, Kakoly NS, Tan JWJ, Fitzgerald G, Khomami MB, Joham AE, Cooray SD, Misso ML, Norman RJ, Harrison CL, et al. Metabolic syndrome in polycystic ovary syndrome: a systematic review, metaanalysis and meta-regression. Obesity Reviews 201920 339-352. (https://doi.org/10.1111/obr.12762)

5 Teede HJ, Misso ML, Deeks AA, Moran LJ, Stuckey BGA, Wong JLA, Norman RJ, Costello MF \& Guideline Development Groups. Assessment and management of polycystic ovary syndrome: summary of an evidence-based guideline. Medical Journal of Australia 2011195 S65-S112. (https://doi.org/10.5694/mja11.10915)

6 Teede HJ, Misso ML, Costello MF, Dokras A, Laven J, Moran L, Piltonen T, Norman RJ \& International PCOS Network. Recommendations from the international evidence-based guideline for the assessment and management of polycystic ovary syndrome. Clinical Endocrinology 201889 251-268. (https://doi.org/10.1111/cen.13795)

7 Cooney LG, Lee I, Sammel MD \& Dokras A. High prevalence of moderate and severe depressive and anxiety symptoms in polycystic ovary syndrome: a systematic review and meta-analysis. Human Reproduction 201732 1075-1091. (https://doi.org/10.1093/humrep/ dex044)

8 Stepto NK, Moreno-Asso A, McIlvenna LC, Walters KA \& Rodgers RJ. Molecular mechanisms of insulin resistance in polycystic ovary syndrome. Unraveling the conundrum in skeletal muscle? Journal of Clinical Endocrinology and Metabolism 2019104 5372-5381. (https:// doi.org/10.1210/jc.2019-00167)

9 Stepto NK, Cassar S, Joham AE, Hutchison SK, Harrison CL, Goldstein RF \& Teede HJ. Women with polycystic ovary syndrome have intrinsic insulin resistance on euglycaemic-hyperinsulaemic clamp. Human Reproduction 201328 777-784. (https://doi. org/10.1093/humrep/des463)

10 Cassar S, Misso ML, Hopkins WG, Shaw CS, Teede HJ \& Stepto NK. Insulin resistance in polycystic ovary syndrome: a systematic review and meta-analysis of euglycaemic-hyperinsulinaemic clamp studies. Human Reproduction 201631 2619-2631. (https://doi.org/10.1093/ humrep/dew243)

11 Moran LJ, Misso ML, Wild RA \& Norman RJ. Impaired glucose tolerance, type 2 diabetes and metabolic syndrome in polycystic ovary syndrome: a systematic review and meta-analysis. Human Reproduction Update 201016 347-363. (https://doi.org/10.1093/ humupd/dmq001)

12 Rodgers RJ, Avery JC, Moore VM, Davies MJ, Azziz R, StenerVictorin E, Moran LJ, Robertson SA, Stepto NK, Norman RJ, et al. Complex diseases and co-morbidities: polycystic ovary syndrome and type 2 diabetes mellitus. Endocrine Connections 20198 R71-R75. (https://doi.org/10.1530/EC-18-0502)

13 Diamanti-Kandarakis E \& Dunaif A. Insulin resistance and the polycystic ovary syndrome revisited: an update on mechanisms and implications. Endocrine Reviews 201233 981-1030. (https://doi. org/10.1210/er.2011-1034)

14 Legro RS, Arslanian SA, Ehrmann DA, Hoeger KM, Murad MH, Pasquali R, Welt CK \& Endocrine Society. Diagnosis and treatment of polycystic ovary syndrome: an Endocrine Society clinical practice guideline. Journal of Clinical Endocrinology and Metabolism 201398 4565-4592. (https://doi.org/10.1210/jc.2013-2350)

15 Stepto NK, Patten R, Tassone EC, Misso ML, Brennan L, Boyle J, Boyle RA, Harrison CL, Hirschberg AL, Marsh K, et al. Exercise recommendations for women with polycystic ovary syndrome: is the

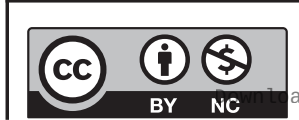

This work is licensed under a Creative Commons Attribution-NonCommercial 4.0 International License. ded from Bioscientifica,com at 04/26/2023 09:24:23AM 
evidence enough? Sports Medicine 201949 1143-1157. (https://doi. org/10.1007/s40279-019-01133-6)

16 Lundsgaard AM \& Kiens B. Gender differences in skeletal muscle substrate metabolism - molecular mechanisms and insulin sensitivity. Frontiers in Endocrinology 20145 195. (https://doi. org/10.3389/fendo.2014.00195)

17 Krook A, Bjornholm M, Galuska D, Jiang XJ, Fahlman R, Myers Jr MG, Wallberg-Henriksson H \& Zierath JR. Characterization of signal transduction and glucose transport in skeletal muscle from type 2 diabetic patients. Diabetes 200049 284-292. (https://doi. org/10.2337/diabetes.49.2.284)

18 Krook A, Roth RA, Jiang XJ, Zierath JR \& Wallberg-Henriksson H. Insulin-stimulated Akt kinase activity is reduced in skeletal muscle from NIDDM subjects. Diabetes 199847 1281-1286. (https://doi. org/10.2337/diab.47.8.1281)

19 Consitt LA, Van Meter J, Newton CA, Collier DN, Dar MS, Wojtaszewski JFP, Treebak JT, Tanner CJ \& Houmard JA. Impairments in site-specific AS160 phosphorylation and effects of exercise training. Diabetes 201362 3437-3447. (https://doi.org/10.2337/db13-0229)

20 Hojlund K, Glintborg D, Andersen NR, Birk JB, Treebak JT, Frosig C, Beck-Nielsen H \& Wojtaszewski JF. Impaired insulin-stimulated phosphorylation of Akt and AS160 in skeletal muscle of women with polycystic ovary syndrome is reversed by pioglitazone treatment. Diabetes 200857 357-366. (https://doi.org/10.2337/db07-0706)

21 Hansen SL, Svendsen PF, Jeppesen JF, Hoeg LD, Andersen NR, Kristensen JM, Nilas L, Lundsgaard AM, Wojtaszewski JFP, Madsbad S, et al. Molecular mechanisms in skeletal muscle underlying insulin resistance in lean women with polycystic ovary syndrome. Journal of Clinical Endocrinology and Metabolism 2018104 1841-1854. (https:// doi.org/10.1210/jc.2018-01771)

22 Raja-Khan N, Urbanek M, Rodgers RJ \& Legro RS. The role of TGFbeta in polycystic ovary syndrome. Reproductive Sciences 201421 20-31. (https://doi.org/10.1177/1933719113485294)

23 Böhm A, Hoffmann C, Irmler M, Schneeweiss P, Schnauder G, Sailer C, Schmid V, Hudemann J, Machann J, Schick F, et al. TGF$\beta$ contributes to impaired exercise response by suppression of mitochondrial key regulators in skeletal muscle. Diabetes 201665 2849-2861. (https://doi.org/10.2337/db15-1723)

24 Seong HA, Manoharan R \& Ha H. Smad proteins differentially regulate obesity-induced glucose and lipid abnormalities and inflammation via class-specific control of AMPK-related kinase MPK38/MELK activity. Cell Death and Disease 20189 471. (https:// doi.org/10.1038/s41419-018-0489-x)

25 Takahashi H, Alves CRR, Stanford KI, Middelbeek RJW, Nigro P, Ryan RE, Xue R, Sakaguchi M, Lynes MD, So K, et al. TGF- $\beta 2$ is an exercise-induced adipokine that regulates glucose and fatty acid metabolism. Nature Metabolism 20191 291-303. (https://doi. org/10.1038/s42255-018-0030-7)

26 Richter EA \& Hargreaves M. Exercise, GLUT4, and skeletal muscle glucose uptake. Physiological Reviews 201393 993-1017. (https://doi. org/10.1152/physrev.00038.2012)

27 Harrison CL, Lombard CB, Strauss BJ \& Teede HJ. Optimizing healthy gestational weight gain in women at high risk of gestational diabetes: a randomized controlled trial. Obesity 201321 904-909. (https://doi. org/10.1002/oby.20163)

28 Hutchison SK, Stepto NK, Harrison CL, Moran LJ, Strauss BJ \& Teede HJ. Effects of exercise on insulin resistance and body composition in overweight and obese women with and without polycystic ovary syndrome. Journal of Clinical Endocrinology and Metabolism 201196 E48-E56. (https://doi.org/10.1210/jc.2010-0828)

29 Hutchison SK, Teede HJ, Rachon D, Harrison CL, Strauss BJ \& Stepto NK. Effect of exercise training on insulin sensitivity, mitochondria and computed tomography muscle attenuation in overweight women with and without polycystic ovary syndrome. Diabetologia 201255 1424-1434. (https://doi.org/10.1007/s00125011-2442-8)
30 Harrison CL, Stepto NK, Hutchison SK \& Teede HJ. The impact of intensified exercise training on insulin resistance and fitness in overweight and obese women with and without polycystic ovary syndrome. Clinical Endocrinology 201276 351-357. (https://doi. org/10.1111/j.1365-2265.2011.04160.x)

31 Meyer C, McGrath BP \& Teede HJ. Overweight women with polycystic ovary syndrome have evidence of subclinical cardiovascular disease. Journal of Clinical Endocrinology and Metabolism 200590 5711-5716. (https://doi.org/10.1210/jc.2005-0011)

32 Benziane B, Burton TJ, Scanlan B, Galuska D, Canny BJ, Chibalin AV, Zierath JR \& Stepto NK. Divergent cell signaling after short-term intensified endurance training in human skeletal muscle. American Journal of Physiology: Endocrinology and Metabolism 2008295 E1427-E1438. (https://doi.org/10.1152/ajpendo.90428.2008)

33 Parker L, Stepto NK, Shaw CS, Serpiello FR, Anderson M, Hare DL \& Levinger I. Acute high-intensity interval exercise-induced redox signaling is associated with enhanced insulin sensitivity in obese middle-aged men. Frontiers in Physiology 20167 411. (https://doi. org/10.3389/fphys.2016.00411)

34 Parker L, Trewin A, Levinger I, Shaw CS \& Stepto NK. The effect of exercise-intensity on skeletal muscle stress kinase and insulin protein signaling. PLoS ONE 201712 e0171613. (https://doi.org/10.1371/ journal.pone.0171613)

35 Prodoehl MJ, Hatzirodos N, Irving-Rodgers HF, Zhao ZZ, Painter JN, Hickey TE, Gibson MA, Rainey WE, Carr BR, Mason HD, et al. Genetic and gene expression analyses of the polycystic ovary syndrome candidate gene fibrillin-3 and other fibrillin family members in human ovaries. Molecular Human Reproduction 200915 829-841. (https://doi.org/10.1093/molehr/gap072)

36 Hopkins WG, Marshall SW, Batterham AM \& Hanin J. Progressive statistics for studies in sports medicine and exercise science. Medicine and Science in Sports and Exercise 200941 3-13. (https://doi. org/10.1249/MSS.0b013e31818cb278)

37 Corbould A, Kim YB, Youngren JF, Pender C, Kahn BB, Lee A \& Dunaif A. Insulin resistance in the skeletal muscle of women with polycystic ovary syndrome involves both intrinsic and acquired defects in insulin signaling. American Journal of Physiology: Endocrinology and Metabolism 2005288 E1047-E1054. (https://doi. org/10.1152/ajpendo.00361.2004)

38 Parker L, Shaw CS, Stepto NK \& Levinger I. Exercise and glycemic control: focus on redox homeostasis and redox-sensitive protein signaling. Frontiers in Endocrinology 20178 87. (https://doi. org/10.3389/fendo.2017.00087)

39 Kleinert M, Sylow L, Fazakerley DJ, Krycer JR, Thomas KC, Oxboll AJ, Jordy AB, Jensen TE, Yang G, Schjerling P, et al. Acute mTOR inhibition induces insulin resistance and alters substrate utilization in vivo. Molecular Metabolism 20143 630-641. (https://doi. org/10.1016/j.molmet.2014.06.004)

40 Bodine SC, Stitt TN, Gonzalez M, Kline WO, Stover GL, Bauerlein R, Zlotchenko E, Scrimgeour A, Lawrence JC, Glass DJ, et al. Akt/mTOR pathway is a crucial regulator of skeletal muscle hypertrophy and can prevent muscle atrophy in vivo. Nature Cell Biology 20013 1014-1019. (https://doi.org/10.1038/ncb1101-1014)

41 Dantas WS, Marcondes JA, Shinjo SK, Perandini LA, Zambelli VO, Neves WD, Barcellos CR, Rocha MP, Yance V dos R, Pereira RT, et al. GLUT4 translocation is not impaired after acute exercise in skeletal muscle of women with obesity and polycystic ovary syndrome. Obesity 201523 2207-2215. (https://doi.org/10.1002/oby.21217)

42 Peck GR, Chavez JA, Roach WG, Budnik BA, Lane WS, Karlsson HK, Zierath JR \& Lienhard GE. Insulin-stimulated phosphorylation of the Rab GTPase-activating protein TBC1D1 regulates GLUT4 translocation. Journal of Biological Chemistry 2009284 30016-30023. (https://doi.org/10.1074/jbc.M109.035568)

43 Tonks KT, Ng Y, Miller S, Coster AC, Samocha-Bonet D, Iseli TJ, Xu A, Patrick E, Yang JY, Junutula JR, et al. Impaired Akt phosphorylation in insulin-resistant human muscle is accompanied by selective and

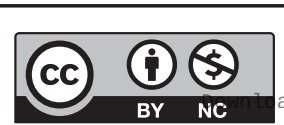

This work is licensed under a Creative Commons Attribution-NonCommercial 4.0 International License. ded from Bioscientifica com at 04/26/2023 09:24:23AM 
heterogeneous downstream defects. Diabetologia 201356 875-885. (https://doi.org/10.1007/s00125-012-2811-y)

44 Newton AC. Regulation of the ABC kinases by phosphorylation: protein kinase $\mathrm{C}$ as a paradigm. Biochemical Journal $2003 \mathbf{3 7 0}$ 361-371. (https://doi.org/10.1042/BJ20021626)

$45 \mathrm{Yu}$ C, Chen Y, Cline GW, Zhang D, Zong H, Wang Y, Bergeron R, Kim JK, Cushman SW, Cooney GJ, et al. Mechanism by which fatty acids inhibit insulin activation of insulin receptor substrate-1 (IRS-1)-associated phosphatidylinositol 3-kinase activity in muscle. Journal of Biological Chemistry 2002277 50230-50236. (https://doi. org/10.1074/jbc.M200958200)

46 Goto-Inoue N, Yamada K, Inagaki A, Furuichi Y, Ogino S, Manabe Y, Setou M \& Fujii NL. Lipidomics analysis revealed the phospholipid compositional changes in muscle by chronic exercise and high-fat diet. Scientific Reports 20133 3267. (https://doi.org/10.1038/srep03267)

47 Cassar S, Teede HJ, Moran LJ, Joham AE, Harrison CL, Strauss BJ \& Stepto NK. Polycystic ovary syndrome and anti-Mullerian hormone: role of insulin resistance, androgens, obesity and gonadotrophins.
Clinical Endocrinology 201481 899-906. (https://doi.org/10.1111/ cen.12557)

48 Tal R, Seifer DB, Shohat-Tal A, Grazi RV \& Malter HE. Transforming growth factor-beta 1 and its receptor soluble endoglin are altered in polycystic ovary syndrome during controlled ovarian stimulation. Fertility and Sterility 2013100 538-543. (https://doi.org/10.1016/j. fertnstert.2013.04.022)

49 Chen JL, Colgan TD, Walton KL, Gregorevic P \& Harrison CA. The TGF- $\beta$ signalling network in muscle development, adaptation and disease. In Growth Factors and Cytokines in Skeletal Muscle Development, Growth, Regeneration and Disease, pp. 97-131. Eds J White \& G

Smythe. Cham, Switzerland: Springer International Publishing, 2016. (https://doi.org/10.1007/978-3-319-27511-6_5)

50 Cassar S, Teede HJ, Harrison CL, Joham AE, Moran LJ \& Stepto NK. Biomarkers and insulin sensitivity in women with polycystic ovary syndrome: characteristics and predictive capacity. Clinical Endocrinology 201583 50-58. (https://doi.org/10.1111/ cen.12619)

Received in final form 27 February 2020

Accepted 31 March 2020

Accepted Manuscript published online 31 March 2020 https://ec.bioscientifica.com

https://doi.org/10.1530/EC-19-0551 (c) 2020 The authors Published by Bioscientifica Ltd

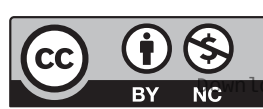

This work is licensed under a Creative Commons Attribution-NonCommercial 4.0 International License. ded from Bioscientifica.com at 04/26/2023 09:24:23AM via free access 